\title{
Preprosthetic Surgery for Severely Atrophic Maxilla with Poor Palatal Vault Form; Report of Two Cases Treated by Hard Palate Compression through Palatal Vault Osteotomy
}

\author{
Minoru HORI ${ }^{1}$, Masahiro OKAUE ${ }^{1}$, Shinko MATSUNAGA ${ }^{1}$, Shinkichi \\ IWANARI ${ }^{1}$, Mitsuhiko MATSUMOTO ${ }^{1}$, Hiroshi TANAKA ${ }^{1}$, Katsuyuki \\ YAMAMOTO $^{2}$ and Yoshihiko MORIYA ${ }^{2}$
}

(Received 18 March and accepted 18 May 1993)

Key words: preprosthetic surgery, maxillary alveolar atrophy, palatal vault osteotomy, hard palate compression

\begin{abstract}
Two cases of severely atrophic maxilla with poor palatal vault form treated by Kitayama's modified palatal vault osteotomy technique are described. The advantages of this osteotomy technique are outlined in comparison with other surgical methods.

\section{Introduction}

A variety of preprosthetic surgical procedures have been developed to improve the supporting base of a prosthesis in patients with an atrophic alveolar ridge ${ }^{[1]}$. These surgical procedures are generally applied to the mandible rather than the maxilla, because severe resorption of the alveolar ridge occurs mostly in the mandible, and only rarely in the maxilla. Occasionally, however, in edentulous patients with severe atrophy of the maxillary alveolar ridge and a flat palatal vault, it is necessary to use preprosthetic surgical techniques on the maxilla to achieve an adequately stable base for a complete maxillary denture ${ }^{[2]}$. In such cases, it is almost always necessary to perform palatal vault osteotomy after augmentation of the alveolar ridge. This paper describes the technique of palatal vault osteotomy used in two patients.
\end{abstract}

\section{Surgical Technique}

The patient is given general oral-endotracheal anesthesia. Local anesthesia is then administered to the surgical field, using 1\% lidocaine with 1:100,000 epinephrine.

A reversed U-shaped incision is made along the crest of the alveolar ridge, between the left and right tuberosities, carried forward on the palatal aspect of the alveolar ridge to the incisive papilla, and then joined with a similar incision from the opposite side. A palatal mucoperiosteal flap is then raised and folded back onto the soft palate. In order to make the palatine foramen visible, the mucoperiosteum is elevated with a periosteal elevator by approximately $5 \mathrm{~mm}$ beyond the planned osteotomy line. The greater palatine arteries can then be clearly seen.

At the posterior border of the hard palate, a small round bur or a fine fissure bur is first used to cut the bone in an arch-shape, taking care to avoid injuring the palatine foramen. The osteotomy is then continued in a reverse U-shape along the palatal aspect of the residual alveolar ridge and continued forward to join an osteotomy from the opposite side. The depth of each osteotomy is carefully assessed so that it just enters the maxillary sinuses.

\footnotetext{
堀 稔, 岡上真裕, 松永心子, 岩成進吉, 松本光彦, 田中 博, 山本克之, 森谷良彦

1 Department of Oral and Maxillofacial Surgery, Nihon University School of Dentistry

2 Department of Complete Prosthodontics, Nihon University School of Dentistry

To whom all correspondence should be addressed: Dr. Hiroshi TANAKA, Department of Oral and Maxillofacial Surgery, Nihon University School of Dentistry, 1-8-13, Kanda-Surugadai, Chiyoda-Ku, Tokyo 101, JAPAN
} 
A further osteotomy is performed along the medial palatal suture, using a reciprocating saw. The bone cut is continued until loss of resistance can be felt at the edge of the nasal septum. A fine chisel is then used to accomplish the lateral cuts on each side of the base of the nasal septum, and thus separate the left and right sides of the hard palate (Fig. 1).

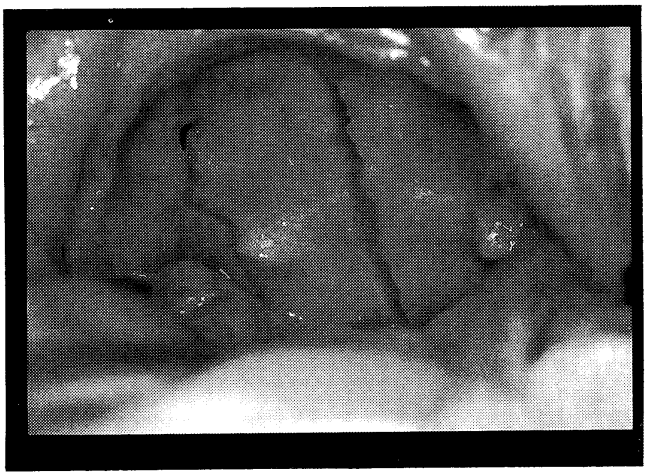

Fig. 1 Photograph illustrating the osteotomy line

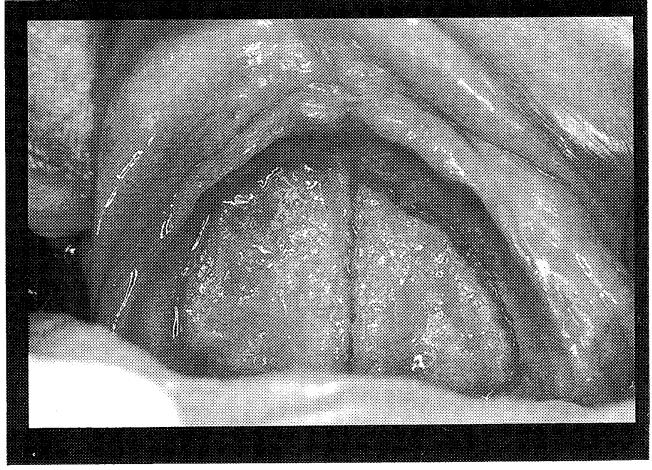

Fig. 2 Photograph showing the prominent nasal septum, after raising the hard palate

The anterior area of the bone section on each side is gently pushed in a superior-lateral direction toward the nasal cavity, to expose the nasal septum. During this process, it is not necessary to hinge down a flap of the hard palate (Fig. 2). Several millimeters of the prominent nasal septum are then removed, and the anterior hard palate is raised superiorily to create a deeper palatal form. In addition to these procedures, if it is necessary to create a satisfactory form for the alveolar ridge, zygomatic alveolar crest compression may be applied simultaneously. The palatal mucoperiosteal flap is then replaced and sutured to cover the new vault. In order to maintain the deepened vault temporarily, and to take an impression of the new vault, modelling compound is added on the patient's denture. The denture is then held in place by circumzygomatic suspension wiring, and is left in situ for approximately 4 weeks.

\section{Case Report}

\section{Case 1}

The patient, a 76-year-old Japanese man, had worn complete maxillary and partial mandibular dentures for 12 years prior to his visit to a general dentist in February 1990. His complaint was that the maxillary denture had recently become loose. A new maxillary denture was made, but a stable, functional fit could not be achieved in spite of several adjustments. The patient was therefore referred to Nihon University Dental Hospital for preprosthetic surgery, on March 15, 1990.

Intra-oral examination showed that the maxillary denture had little resistance to anteroposterior force. The alveolar ridge, which was composed mainly of freely movable gingiva with little supporting bone, was severely deficient, especially between the right and left premolar regions. As a result, the zygomatic alveolar crest and the anterior nasal spine were palpable close to the residual alveolar ridge. In addition to this atrophied alveolar ridge, the form of the palatal vault was moderately flattened.

Panoramic and tomographic X-ray films revealed total resorption of the alveolar ridge, a flat palatal vault and close proximity of the alveolar ridge to the anterior nasal aperture and maxillary sinus floor (Fig. 3).

As an initial procedure, the atrophied alveolar ridge corresponding to $4+4$ was augmented with hydroxyapatite particles using the tunneling procedure. After 2 months, the hydroxyapatite had become firm, and the contour of the alveolar ridge had improved. A temporary maxillary 


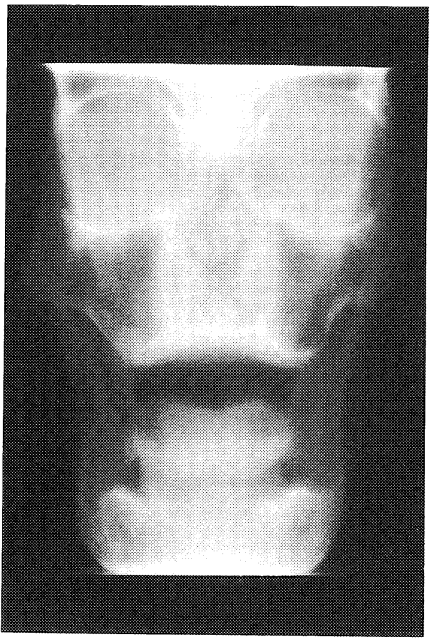

Fig. 3 Preoperative tomographic radiograph of Case $l$ showing the flattened palatal vault form

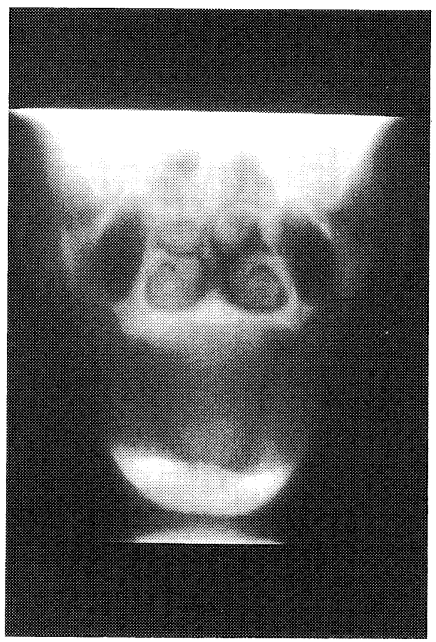

Fig. 4 Preoperative tomographic radiograph of Case 2 showing the severely flattened palatal vault form

denture was then made on the improved alveolar ridge. On June 26, 1990, a palatal vault osteotomy and zygomatic alveolar crest compression were performed at the Department of Oral and Maxillofacial Surgery.

Case 2

The patient, a 56-year-old Japanese woman, had worn complete maxillary and mandibular dentures for 10 years. Five years previously, she had visited her general dentist complaining of loose fit of the maxillary denture. New dentures were made, but the patient had to use a silicone soft liner to deal with continuing problems of fit. The patient visited a prosthodontist at Nihon University Dental Hospital to overcome these problems, and was referred for preprosthetic surgery on April 6, 1992.

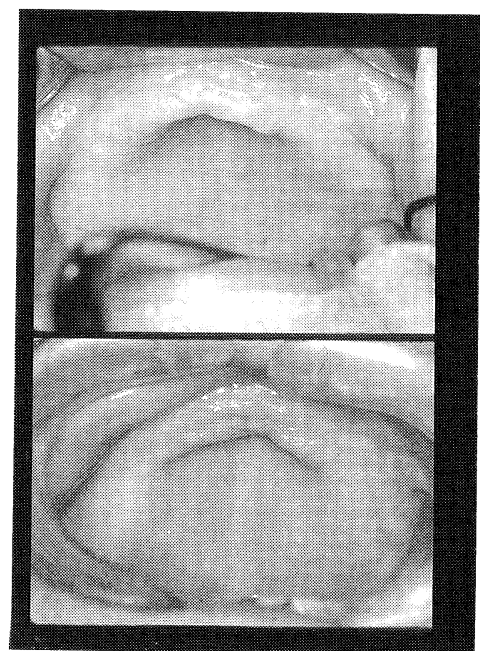

Fig. 5 Intraoral view of Case 1

Above : preoperative view

Below : postoperative view, showing the adequate depth of the palatal vault resulting from augmentation with hydroxyapatite combined with palatal vault osteotomy

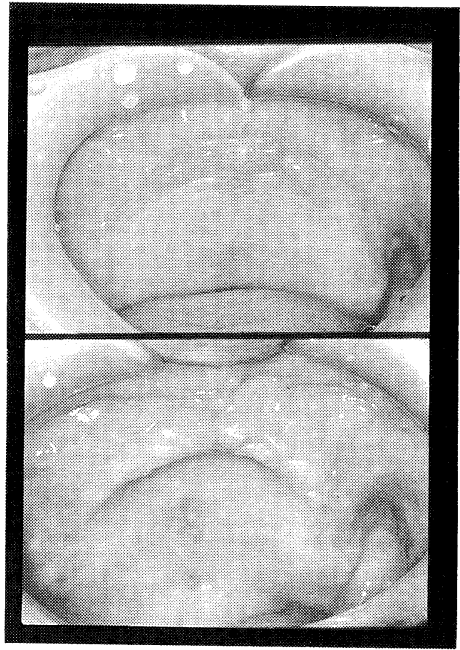

Fig. 6 Intraoral view of Case 2

Above : preoperative view

Below : postoperative view, showing the adequate depth of the palatal vault resulting from augmentation with hydroxyapatite combined with palatal vault osteotomy 
Intra-oral examination showed that the patient had an edentulous maxilla and mandible. The maxillary and mandibular alveolar ridges were severely atrophied. Consequently, the patient had the habit of continuously using her tongue to hold the maxillary denture in place during use. The maxillary alveolar ridge, especially in the area corresponding to 5$\rfloor$ to $\lfloor 4$, was extremely resorbed, and as a result the palatal vault was severely flattened. The anterior portion of the mandibular alveolar ridge was almost completely resorbed, so that the mental spine was easily palpable. The vestibular mucosae were attached near to the crests of the ridges in both jaws. In terms of alveolar resorption of the maxilla, this case was more severe than Case 1.

Panoramic and tomographic X-rays confirmed the severe resorption of the maxillary and

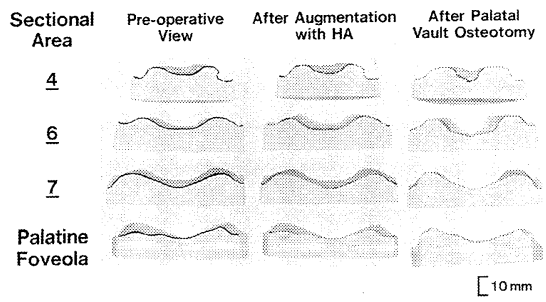

Case 1

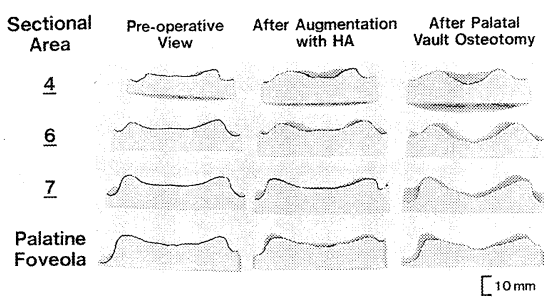

Case 2

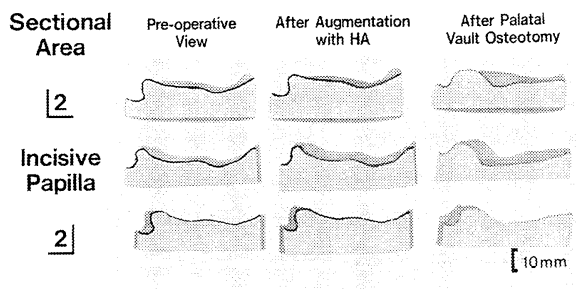

Case 1

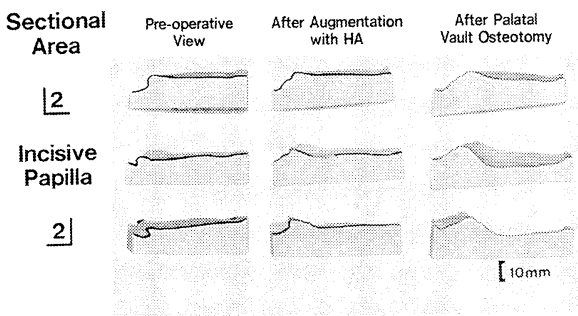

Case 2
Fig. 7 Case 1 and Case 2 : Photographs of crosssections of maxillary casts showing the increased depth of the palatal vault (frontal section)
Fig. 8 Case 1 and Case 2 : Photographs of crosssections of maxillary casts showing the increased depth of the palatal vault (sagittal section)

mandibular alveolar ridges, leaving only a few millimeters of bone at the inferior margins of the maxillary sinus, (Fig. 4).

On April 6, 1992, augmentation of the maxillary and mandibular alveolar ridges was performed, using the same material and technique as in Case 1. On August 27, 1992, a palatal vault osteotomy was performed at the Department of Oral and Maxillofacial Surgery.

Postoperative clinical photographs showed an adequate palatal vault form (Figs. 5 and 6). Also, cross-sections of the postoperative maxillary casts showed improvement in the palatal vault forms, especially in the anterior hard palate (Figs. 7 and 8).

\section{Discussion}

It is very difficult to achieve a satisfactory fit for complete maxillary dentures in patients with edentulous flat palatal vaults. When severely atrophied alveolar ridges are also present, adequate fitting of dentures becomes even more difficult.

Fonseca, Frost, Zeitler and StoelingA ${ }^{[2]}$ have categorized the bone deficiency states of the 
maxilla as follows:

1. Total maxillary atrophy with poor palatal vault form ;

2. Total maxillary atrophy with acceptable palatal vault form ;

3. Regional problems ;

a. Anterior atrophy;

b. Posterior atrophy;

c. Undercut regions.

They recommended radical surgical techniques in these cases, including onlay bone grafts, interpositional bone grafts, and palatal osteotomies. Further techniques are also available: for example, bone grafts to augment the atrophic ridge together with autogenous particulate cancellous bone grafts ${ }^{[3]}$, or hydroxyapatite reconstruction of the alveolar ridge with an open mucosal flap technique ${ }^{[4]}$. However, in some cases, such as those described in this paper, a combination of techniques is indicated. There are two major goals in these cases: to acquire a satisfactory interridge relationship and to create an adequate palatal vault form. To achieve these goals, onlay bone grafting is not indicated because of the lack of overlying soft tissue, which makes it extremely difficult to apply this technique to the anterior alveolar ridge. Particulate cancellous bone grafting is also unsuitable, because of severe postoperative resorption. To avoid these problems and to achieve the required goals, palatal vault osteotomy preceded by augmentation using hydroxyapatite particles is recommended.

WASSMUND $^{[5]}$ first reported the palatal vault osteotomy technique in 1931 . However, it was seldom used for many years, because of its difficulty in producing a satisfactory palatal vault form, and postoperative damage to the nasal floor membrane through excessive secretion into the nasal cavity ${ }^{[6,7]}$. STEINHÄUSER ${ }^{[8]}$ modified the technique by using two sagittal osteotomies on each side of the palatal suture. However, this technique did not prevent damaging postoperative secretions. In 1981, Yoshizawa et al. ${ }^{[9]}$ reported a further modification of the palatal vault osteotomy along the medial palatal suture together with intraoral removal of the inferior nasal septum. However, postoperative healing of this osteotomy line may be incomplete. To overcome this problem, KITAYAmA et al. ${ }^{[10]}$ in 1987 introduced a further modification which, by not using a hinged-down flap of the hard palate, did not expose the nasal floor, and which reduced the prominent nasal septum rather than removing it. KITAYAMA's modified palatal vault osteotomy technique thus achieves the major goals of this form of surgery. It creates a good anterior palatal vault form, while minimizing damage to the nasal cavity which may cause postoperative problems. It is therefore recommended for patients with an extremely flat palatal vault form.

\section{Conclusion}

Two patients, who had severely flattened palatal vault forms with atrophic maxillary alveolar ridges, were treated with KITAYAMA's modified palatal vault osteotomy technique.

Some operative techniques were discussed in contrast with KITAYAMA's original method.

\section{References}

[1] Tucker, M. R.: Advanced preprosthetic surgery. In Contemporary Oral and Maxillofacial Surgery, 331-364, Peterson, L. J., Ellis, E. III., Hupp, J. R. and Tucker, M. R., eds., C. V. Mosby Co., St. Louis, U. S. A., 1988

[2] Fonseca, R. J., Frost, D., Zeitler, D. and Stoelinga, P. J. W.: Osseous reconstruction of edentulous bone loss. In Reconstructive Preprosthetic Oral and Maxillofacial Surgery, 117-165, FonsECA, R. J. and DAvis, W. H., eds., W. B. Saunders Co., Philadelphia, U. S. A., 1986

[3] Boyne, P. J., Cole, M. D., Stringer, O. and Shafqat, J.: A technique for osseous reconstruction of deficient edentulous maxillary ridges, J. Oral Maxillofac. Surg., 43, 87-91, 1985

[4] LEw, D.: A method for augmenting the severely atrophic maxilla using hydroxyapatite, J. Oral Maxillofac. Surg., 43, 57-60, 1985

[5] Wassmund, M.: Über chirugische formgestatung des atrophischen Kiefers zum Zwecke prosthetischer Verosorgung, Vrtl. Jhrshr. Zahnhk., 47, 305-319, 1931 
[6] Charest, A. and Goodyer, V.: Palatal osteotomy: a simple approach to maxillary alveolar atrophy, J. Oral Surg., 34, 442-444, 1976

[7] Leonard, M. and Howe, G. L.: Palatal vault osteotomy, J. Oral Surg., 46, 344-348, 1978

[8] Steinhäuser, E. W.: Methoden zur operativen Verbesserung der Gaumenwölbung, Zahnärztl. Prax., 29, 50-54, 1978

[9] Yoshizawa, N., Shimada, K., Yanai, T., Shibata, H., Yamada, M., Kawashima, Y., Saito, C. and Takahashi, S.: Hard palate compression for greatly reduced alveolar ridge of the maxilla, Jpn. J. Oral Maxillofac. Surg., 27, 1602-1608, 1981

[10] Kitayama, S., Oda, H., Nagano, T., Shibata, Y., Kondou, K. and Toyoda, T.: A modification of hard palate compression for marked atrophic maxilla, Jpn. J. Oral Maxillofac. Surg., 33, 791-796, 1987 